\title{
The incidence of associated fractures of the upper limb in fractures of the radial head
}

\author{
Laurens Kaas $\cdot$ Roger P. van Riet $\cdot$ \\ Jos P. A. M. Vroemen · Denise Eygendaal
}

Received: 23 March 2008/Accepted: 23 June 2008/Published online: 10 July 2008

(C) Springer-Verlag 2008

\begin{abstract}
Radial head fractures are common injuries. In American publications, one-third of the patients with these fractures have been shown to have associated injuries. The aim of this retrospective study is to describe the epidemiology of radial head fractures and associated fractures of the ipsilateral upper extremity in a European population. This study describes the epidemiology of radial head and associated fractures of the upper extremity in a Dutch population by a retrospective radiographic review of all patients with a radial head fracture between 1 January 2006 and 1 July 2007. A total of 147 radial head fractures were diagnosed in 145 patients. The incidence in the general population was 2.5 per 10.000 per year. The average age was 45.9 (SD 17.3) years and male-female ratio was 2:3. The mean age of males was significantly lower (37.1, SD 14.2 years) than of women (53.9, SD 16.4 years). Associated fracture of the upper extremity was found in $10.2 \%$. Coronoid fractures were most common (4.1\%). Associated upper limb fractures in patients with a radial head fracture are common in the European population. It is of clinical importance to suspect associated lesions and to perform a
\end{abstract}

\footnotetext{
L. Kaas · D. Eygendaal $(\bowtie)$

Department of Orthopaedic Surgery, Amphia Hospital, Molengracht 21, 4818CK Breda, The Netherlands e-mail: deygendaal@amphia.nl

L. Kaas

e-mail: laurenskaas@hotmail.com

R. P. van Riet

Department of Orthopaedic Surgery, Monica Hospital, Florent Pauwelsei 1, 2100 Antwerp, Belgium

J. P. A. M. Vroemen

Department of General Surgery, Amphia Hospital,

Molengracht 21, 4818CK Breda, The Netherlands
}

thorough physical examination and additional radiological examination on demand.

Keywords Radial head fracture · Associated injury · Epidemiology

\section{Introduction}

Radial head fractures are common and account for onethird of all fractures of the elbow and approximately 1.7$5.4 \%$ of all fractures in adults [1,2]. Eighty-five percentage of radial head fractures occur in patients between 20 and 60 years of age and approximately one-third of the patients have associated injuries, such as a fracture or ligamentous injury of the hand, wrist, forearm, humerus or shoulder $[1,3,4]$. Radial head fractures usually result from a fall on an outstretched arm with the elbow in pronation and partial flexion or, in rare cases, direct trauma [5, 6].

Radial head fractures can be classified according to the Mason-Johnston classification, based on 100 cases (see Table 1) [7]. Mason type 1 fractures are treated conservatively with early mobilisation. Type 2 fractures (with over $2 \mathrm{~mm}$ dislocation or over one-third of the articular surface) are treated with open reduction and internal fixation (ORIF). Type 3 and 4 fractures can be treated with ORIF or excision of the radial head and ligamentous repair or reconstruction, usually followed by prosthetic replacement $[2,8,9]$.

The Mason-Johnston classification does not consider soft-tissue injury or associated elbow and forearm injuries. More recent classifications do consider these types of injury as recent literature shows the importance of associated injury, such as coronoid fractures, for an adequate treatment of radial head fractures [2, 10, 11]. Based on 372 
Table 1 The Mason-Johnston classification of radial head fractures [7]

\begin{tabular}{ll}
\hline Mason type & Description \\
\hline 1 & $\begin{array}{l}\text { Non-displaced fracture } \\
\text { Minimal displacement with angulation or } \\
\text { impression }(>2 \mathrm{~mm})\end{array}$ \\
3 & Comminuted fracture with dislocation \\
4 & Radial head fracture with luxation of the \\
& elbow \\
\hline
\end{tabular}

reviewed cases, van Riet and Morrey [12] recently published their modification of the Mason classification (Table 2). Radial head fractures are classified according to their type (I-III) and a suffix is added for articular or ligamentous injuries when they occur. A "c" is added for coronoid fractures and an "o" for an olecranon fracture. Ligamentous injuries are noted as " $\mathrm{m}$ ", "l," or "d" for medial collateral ligament, lateral collateral ligament or distal radio-ulnar joint lesions. Coronoid fractures are common associated injuries in radial head fractures and can be classified by the Regan and Morrey classification: type 1 is an avulsion fracture, a fracture of $<50 \%$ of the coronoid is a type 2 and $>50 \%$ of the coronoid process is a type 3 fracture (see Table 3) $[4,10]$.

Little is known about the incidence of radial head fractures and associated injuries in the European population. The goal of this retrospective study is to describe the epidemiology of radial head fractures and associated fractures of the ipsilateral upper extremity in a Dutch population.

\section{Methods}

A retrospective database search was performed to identify all patients with radial head fractures who visited the Emergency Department (ED) of the Amphia Hospital (Breda, The Netherlands) in the period between 1 January 2006 and 1 July 2007. This ED provides a region of 400.000 inhabitants of acute medical care. In this period, about 66.000 patients visited the ED. Radiographs of patients with radial head fractures were reviewed by LK

Table 2 Van Riet and Morrey classification of radial head fractures and their associated injuries

\begin{tabular}{lll}
\hline Type of radial head fracture & Associated injury & Suffix \\
\hline I & Articular & $\mathrm{c}, \mathrm{o}$ \\
II & Ligamentous & $\mathrm{m}, \mathrm{l}, \mathrm{d}$ \\
III & & \\
\hline
\end{tabular}

$c$ Coronoid process, $o$ olecranon, $m$ medial collateral ligament,

$l$ lateral collateral ligament, $d$ distal radio-ulnar joint [12]
Table 3 The Regan and Morrey classification of coronoid fractures [10]

\begin{tabular}{ll}
\hline Type of coronoid fracture & Description \\
\hline 1 & Avulsion fracture \\
2 & Fracture of $<50 \%$ of the coronoid \\
3 & Fracture of $>50 \%$ of the coronoid \\
\hline
\end{tabular}

and RvR, and gender, age, side, type of radial head fracture according to the Mason-Johnston classification and associated osseous injuries were documented.

Coronoid fractures were classified according to the Regan and Morrey classification (see Table 3). The Student's $t$ test was used to analyse the significance in age between men and women. The Chi-square test was used to statistically analyse differences between men and women for type of fracture. A $P$ value smaller than 0.05 was considered as statistically significant.

\section{Results}

A total of 147 fractures of the radial head were diagnosed in 145 patients in the period between 1 January 2006 and 1 July 2007; an incidence in the general population of 2.5 per 10.000 per year. Two patients $(1.4 \%)$ had bilateral radial head fractures. Seventy-eight patients presented with a radial head fracture on the left side $(53.8 \%)$ and 65 patients had right sided fractures $(44.5 \%)$. The male-female ratio was $2: 3 ; 58$ males $(40 \%)$ and 87 females $(60 \%)$. The mean age was 45.9 (range 15-87, SD: 17.3 ) years. The mean age of men (37.1, SD 14.2, range 15-73 years) was significantly $(P<0.05)$ lower than the mean age of women $(53.9$, SD 16.4, range 15-87 years).

A total of $50.3 \%(n=74)$ of the radial head fractures were a Mason type 1 , of which $5.3 \%(n=4)$ had an associated fracture; $36.1 \%(n=53)$ were Mason type 2 fractures, of which $7.5 \%(n=4)$ had associated fractures; $8.8 \%(n=13)$ of the patients had a Mason type 3 fracture, of which $15.4 \%(n=2)$ had associated fractures; $71.4 \%$ $(n=5)$ of the patients with a Mason type 4 fracture $(4.8 \%, n=7)$ had associated fractures (see Table 4). There was no significant difference between men and women for type of fracture $(P=0.997)$. A total of 15 patients $(10.2 \%)$ had at least one associated fracture.

Thirteen associated fractures were located in the elbow and six associated fractures occurred in the hand, wrist or forearm. Six coronoid fractures were found $(4.1 \%)$. Four of these were a type 1 fracture, according to the Regan and Morrey classification. Two patients had a type 2 coronoid fracture. Five coronoid fractures were diagnosed with Mason type 4 radial head fractures. One coronoid fracture 
Table 4 Number of radial head fractures, mean age and associated fractures divided by Mason-Johnston classification

\begin{tabular}{lllll}
\hline Mason type & 1 & 2 & 3 & 4 \\
\hline Number (\%) & $74(50.3 \%)$ & $53(36.1 \%)$ & $13(8.8 \%)$ & $7(4.8 \%)$ \\
Male & 28 & 22 & 5 & 3 \\
Female & 46 & 31 & 8 & 4 \\
Associated fractures in \% $(n)$ & $5.4 \%(4)$ & $7.5 \%(4)$ & $15.4 \%(2)$ & $71.4 \%(5)$ \\
Mean age (SD) & $42.2(18.2)$ & $49.8(13.7)$ & $50.5(22.8)$ & $52.9(11.3)$ \\
\hline
\end{tabular}

Table 5 Associated fractures with radial head fractures

\begin{tabular}{llll}
\hline Associated fractures & Number & $\begin{array}{l}\% \text { of } \\
\text { total }\end{array}$ & $\begin{array}{l}\% \text { of } \\
\text { fractures }\end{array}$ \\
\hline Coronoid process & 6 & 4.1 & 32 \\
Scaphoïd fracture & 4 & 2.7 & 21 \\
Olecranon fracture & 1 & 0.7 & 5 \\
Radial diaphysis fracture & 1 & 0.7 & 5 \\
Proximal ulna fracture & 1 & 0.7 & 5 \\
Capitulum fracture & 1 & 0.7 & 5 \\
Triquetrum avulsion fracture & 1 & 0.7 & 5 \\
Radial head luxation & 1 & 0.7 & 5 \\
Essex-Lopresti injury & 1 & 0.7 & 5 \\
Medial epicondyl fracture of the humerus & 1 & 0.7 & 5 \\
Dorsal avulsion fracture of the distal & 1 & 0.7 & 5 \\
$\quad$ humerus & & & \\
Total & 19 & $10.2 \%$ & $100 \%$ \\
\hline
\end{tabular}

was seen with a Mason type 1 fracture. Four (2.7\%) scaphoid fractures were diagnosed. Olecranon fractures, radial diaphysis fractures, capitulum fractures, triquetrum avulsion fractures and medial epicondyl fractures of the humerus were seen in $0.7 \%(n=1)$ of the patients. One $(0.7 \%)$ Essex-Lopresti injury and one $(0.7 \%)$ radial head luxation were diagnosed (see Table 5). A 'terrible triad' of the elbow (a medial collateral ligament tear, radial head fracture and a coronoid fracture) was seen in five patients (3.4\%). No osseous injuries were found proximal to the elbow.

\section{Discussion}

In the period between 1 January 2006 and 1 July 2007 the incidence of radial head fractures in this general Dutch population was 2.5 per 10.000 per year. The mean age was 45.9 years. On average, men sustained a radial head fracture at a significantly younger age (37.1 years) than women (53.9 years). The male-female ratio in this study was 2:3. Previous publications show male-female ratios varying between $1: 1$ and $3: 2$ [1, 4, 13, 14].

In 2005, van Riet et al. [4] described in a similar study of an American population associated fractures in $23 \%$ of
333 radial head fractures, compared to $10.2 \%$ in this study. This difference may be explained because relatively more Mason type 3 fractures were diagnosed in the population of van Riet et al. (19.2\% compared to $13.6 \%$, Mason type 3 and 4). This could be due to the expertise function of the hospital the patients were referred to and Mason type 4 fractures were regarded as Mason type 3 fractures with dislocation.

Coronoid fractures were also the most common associated fractures in the study of van Riet et al. [4]: $16 \%$ of all patients, compared to $4.1 \%$ in this study. These fractures are common with dislocations of the elbow and can be part of a 'terrible triad' of the elbow [15]. Certain types of coronoid fractures are an indication for operative treatment. Inadequately treated coronoid fractures can lead to persistent posterolateral instability and an increased risk of early degeneration of the ulnohumeral joint $[10,16,17]$. In the current study, scaphoid fractures were in this study diagnosed in $2.7 \%$ of all patients, which is similar to the approximately $2 \%$ found by van Riet et al. [4].

Associated soft tissue injuries, such as of ligaments and cartilage, can also occur in radial head fractures [4, 18]. The medial collateral ligament (MCL), especially the anterior band, functions as a major primary stabiliser of the elbow, with the radial head as a secondary stabiliser. Injuries to these structures may result in valgus instability of the elbow. If the MCL is ruptured, the radial head becomes the primary valgus stabiliser. Therefore, the radial head should not be resected in case of MCL injury [19, 20]. So ligamentous instability is of clinical importance, but usually cannot be diagnosed with routine radiographic examination and was therefore not reviewed in this study.

The incidence of associated, osseous injuries of the upper limb in radial head fractures is high. The treating physician should be aware of this and should apply thorough physical examination of the upper limb in every patient with radial head fracture; additional radiological examination can be indicated.

Acknowledgments All authors made significant contributions to the planning or data collection/interpretation, writing or revision of the manuscript, and approval of the final manuscript. Conception and design: D. E., L. K. Data collection and interpretation: L. K., D. E., R. v R., J. V. Writing of the manuscript: L. K., D. E. Revision of the manuscript: L. K., R. v R., J. V., D. E. Approval of the final manuscript: L. K., R. v R., J. V., D. E. 


\section{References}

1. Mason ML (1954) Some observations on fractures of the head of the radius with a review of one hundred cases. Br J Surg 42: 123-132

2. Morrey BF (2000) Radial head fracture. In: Morrey BF (ed) The elbow and its disorders. WB Saunders, Philadelphia, pp 341-363

3. Jackson JD, Steinmann SP (2007) Radial head fractures. Hand Clin 23:185-193

4. Van Riet R, Morrey BF, O’Driscoll SW, Van Glabbeek F (2005) Associated injuries complicating radial head fractures: a demographic study. Clin Orthop Relat Res 441:351-355

5. Amis AA, Miller JH (1995) Mechanisms of elbow fractures: an investigation using impact tests in vitro. Injury 26:163-168

6. McGinley JC, Hopgood BC, Gaughan JP, Sadegiphour K, Kozin SH (2003) Forearm injury and elbow injury: the influence of rotational position. J Bone Joint Surg Am 12:2403-2409

7. Johnston GW (1962) A follow-up of 100 cases of fracture of the head of the radius with review of the literature. Ulster Med $\mathbf{J}$ 31:51-56

8. Van Glabbeek F, Van Riet R, Verstreken J (2001) Current concepts in the treatment of radial head fractures in the adult: A clinical and biomechanical approach. Acta Orthop Belg 67: 430-441

9. Crenshaw AH (2003) Fractures of shoulder, arm and forearm. In: Canale ST (ed) Campbell's operative orthopaedics. Mosby, Philadelphia, pp 2985-3069

10. Regan W, Morrey BF (1989) Fractures of the coronoid process of the ulna. J Bone Joint Surg 71A:1348-1354
11. Sanchez-Sotelo J, O'Driscoll SW, Morrey BF (2005) Medial oblique compression fracture of the coronoid process of the ulna. J Shoulder Elbow Surg 14:60-64

12. Van Riet RP, Morrey BF (2008) Documentation of associated injuries occurring with radial head fracture. Clin Orthop Relat Res 466:130-134

13. Fuchs S, Chylarecki C (1999) Do functional deficits result from radial head resection? J Shoulder Elbow Surg 8:247-251

14. Davidson PA, Moseley JB, Tullos HS (1993) Radial head fracture: a potential complex injury. Clin Orthop Relat Res 297:224-230

15. Doornberg JN, Ring D (2006) Coronoid fracture patterns. J Hand Surg 31A:45-52

16. Closkey RF, Goode JR, Kirschenbaum D, Cody RP (2000) The role of the coronoid process in elbow stability: a biomechanical analysis of axial loading. J Bone Joint Surg Am 82A:1749-1753

17. Ring D (2006) Fractures of the coronoid process of the ulna. J Hand Surg 31A:1679-1681

18. Itamura J, Roidis N, Mirzayan R, Vaishnav S, Learch T, Shean C (2005) Radial head fractures: MRI evaluation of associated injuries. J Shoulder Elbow Surg 14:421-424

19. Hotchkiss RN, Weiland AJ (1987) Valgus instability of the elbow. J Orthop Res 5:372-377

20. Morrey BF, Tanaka S, An KN (1991) Valgus instability of the elbow. A definition of primary and secondary constraints. Clin Orthop 265:187-195 